\title{
Detection criteria for managing trawl impacts on vulnerable marine ecosystems in high seas fisheries of the South Pacific Ocean
}

\author{
Steven J. Parker ${ }^{1, *}$, Andrew J. Penney ${ }^{2}$, Malcolm R. Clark ${ }^{3}$ \\ ${ }^{1}$ National Institute of Water and Atmospheric Research, PO Box 893, Nelson, New Zealand \\ ${ }^{2}$ Ministry of Fisheries, PO Box 1020, Wellington, New Zealand \\ ${ }^{3}$ National Institute of Water and Atmospheric Research, Private Bag 14901, Wellington, New Zealand
}

\begin{abstract}
The United Nations General Assembly resolution 61/105 calls for States to protect vulnerable marine ecosystems (VMEs), including cold-water corals, from destructive fishing practices in international waters. In response, the developing South Pacific Regional Fishery Management Organisation (SPRFMO) adopted interim measures requiring participating states to assess whether individual bottom fishing activities encounter VMEs, and to prevent significant adverse impacts on VMEs, including requiring vessels to cease fishing and move away from such areas. Criteria were developed to identify VMEs from trawl fishery bycatch data and other available scientific information. The criteria integrate information about the vulnerable taxa present, their relative abundance as bycatch, evidence from previous fishery interactions in the area, the degree of habitat isolation and an index of taxonomic distinctness. We also analysed observer data from previous fishing by New Zealand vessels to evaluate the use of bycatch thresholds to trigger a move-on rule in the SPRFMO area. A focus on documenting the distribution of vulnerable taxa and habitat associations through the most robust survey and habitat modelling means feasible will facilitate identifying representative spatial closures for long-term protection of VMEs.
\end{abstract}

KEY WORDS: Vulnerable marine ecosystems $\cdot$ VME $\cdot$ Deep-sea coral $\cdot$ Benthic impacts $\cdot$ Move-on rule $\cdot$ High seas

Resale or republication not permitted without written consent of the publishe

\section{INTRODUCTION}

All benthic marine ecosystems are vulnerable to anthropogenic disturbance to some degree. Fishing with gears that make contact with the bottom has the potential to significantly affect the abundance and diversity of benthic species (Kaiser 1998, Koslow et al. 2001, Clark \& Koslow 2007). Some of the most fragile and ecologically vulnerable species are those that form complex structures which other species may use as habitat or associate with for other purposes such as shelter from predation (Auster 2005, Buhl-Mortensen \& Mortensen 2005). Recent studies indicate that, in the cold waters of the deep ocean, these structure-forming organisms are typically extremely slow growing and long lived (e.g. Adkins et al. 2004, Tracey et al. 2007, Roark et al. 2009), making them slow to recover and even more vulnerable to impacts from fishing (Koslow et al. 2001, Clark et al. 2006, Rogers et al. 2008). Benthic ecosystems that consist of organisms with these characteristics can be significantly impacted by fishing activities and may be considered to be vulnerable marine ecosystems (VMEs) (FAO 2008, Rogers et al. 2008). In international waters of the South Pacific, bottom trawl fisheries target orange roughy Hoplostethus atlanticus, beryx Beryx spp., deep-sea cardinalfish Epigonus telescopus, black oreo Allocyttus niger and other species in 200 to $1200 \mathrm{~m}$ depths, often on the upper reaches of seamounts. Bottom long-lining also occurs in 200 to $800 \mathrm{~m}$, mainly for bluenose Hyperoglyphe antarctica (SPRFMO 2008).

The United Nations General Assembly (UNGA) resolution 61/105 calls for states and regional fisheries management organisations (RFMOs) to assess impacts 
and avoid significant adverse impacts on VMEs from destructive fishing practices in managed international waters (UNGA 2007). In response, the developing South Pacific Regional Fisheries Management Organisation (SPRFMO) adopted interim measures in May 2007 requiring participating states to assess whether individual bottom fishing activities are likely to encounter VMEs within the SPRFMO area. In areas where VMEs are known or likely to occur, States are required to implement adequate mitigation measures to prevent significant adverse impacts. In areas where there is little information available to assess the likelihood of occurrence of VMEs, the interim measures require a process to detect evidence of VMEs while fishing, to cease fishing within 5 nautical miles (n miles) of those areas, to report such encounters and to include such areas in mitigation plans for preventing significant adverse impacts (SPRFMO 2007). New Zealand has developed a policy to implement these measures for New Zealand permitted vessels operating in high seas areas of the South Pacific (Penney et al. 2008, 2009, this Theme Section).

\section{IMPLEMENTING PROTECTION MEASURES}

New Zealand implemented the SPRFMO interim measures in a spatially tiered manner (Penney et al. 2009). Vessels are only allowed to fish in areas designated as 'open' (previously heavily fished) or 'moveon' (previously moderately fished) within the footprint of the 2002-2006 trawl fishery, which limits impacts to $88673 \mathrm{~km}^{2}$. This amounts to $0.16 \%$ of the SPRFMO convention area or $16 \%$ of the SPRFMO area seabed shallower than $2000 \mathrm{~m}$ (see Penney et al. 2009 for bottom trawl footprint characterisation). In approximately half of this open area (where previous effort has been moderate), a move-on rule has been implemented that requires vessels to monitor for evidence of interaction with a VME and to cease fishing within $5 \mathrm{n}$ miles of that fishing site if evidence is found. These actions create higher protection levels for areas in the current trawl footprint with moderate fishing effort and where there is more uncertainty regarding the existence of VMEs (Penney et al. 2008). However, they also require definitions and a protocol for immediate detection of evidence of encounters with VMEs during individual trawl fishing operations at sea.

\section{ASSESSING EVIDENCE OF A VME}

Even within the trawling footprint, not every part of the seabed has been fished, and newly fished sites may contain VMEs. Using a move-on rule to protect VMEs assumes that fishing impacts can be detected and, when evidence of interaction with a VME is encountered, further impact on that VME can be prevented by moving to an alternative area. This could however, have significant negative impacts on nearby VMEs. The effect will depend on the size, patchiness, spatial distribution and separation between VMEs, which are all currently unknown. Evidence to date from video transects in several seamount and ridge systems indicates that these vulnerable communities are typically small, patchy and likely distributed in restricted areas where substrate, currents, and therefore their food sources, are most favourable (Rowden et al. 2005, Clark et al. 2006).

Move-on rules require a trigger based on benthic bycatch data observed in real time from the catch of each individual trawl tow. This is best achieved by $100 \%$ coverage by trained observers, as is required by the SPRFMO interim measures and implemented by New Zealand for bottom trawl vessels fishing in the SPRFMO area. But which taxa should be monitored? The Fisheries and Agriculture Organization (FAO) of the UN has produced guidelines for protecting VMEs from fishing impacts and lists a number of taxonomic groups to be considered. But they also leave managers the discretion to mould the list to regional fisheries and ecologies (FAO 2008). We identified taxonomic groups as vulnerable if their members were typically (1) fragile relative to trawl gear; (2) functionally significant to the community or ecosystem, either by creating structural complexity that other species may utilize as habitat or by providing some unique function that supports the community; (3) unique, rare or endemic to a small area; or (4) low productivity species due to life history traits such as slow growth, high longevity, low fecundity or unpredictable recruitment. In determining the taxa to monitor in South Pacific bottom trawl fisheries, we added 2 other criteria. First, the taxa needed to be retained to some degree and have been previously observed in bottom trawl gear. Second, the taxa must be readily identifiable by scientific observers on board without the aid of complex characters, such as number of polyps $\mathrm{cm}^{-1}$ or ratios of meristics, dissecting microscopes or other complicated protocols.

Combining these criteria, we developed a list of taxonomic groups we define as taxa vulnerable to bottom trawl gear in the South Pacific Ocean (Table 1). Note that because these taxa are typically phyla, orders or families, they may include some members that as a species would not be vulnerable because of its specific life history, productivity or size. These groups contain species that form complex and emergent biogenic benthic structures, are typically fragile and therefore easily damaged by fishing gears, and are likely to be long lived and slow to recover. Species-specific lists would 
Table 1. List of 10 taxonomic groups assessed as vulnerable to bottom trawl fishing in the South Pacific Ocean. Habitat indicators are those groups that are often found in association with vulnerable marine ecosystem (VME) taxa and indicate that habitat associated with a VME is present. Note: taxa associated with seep/vent systems could be included in principle, but specific seep and vent taxa have not yet been identified in fishery data

\begin{tabular}{|ll|}
\hline Taxonomic level & Common name \\
\hline Vulnerable taxa & \\
Phylum Porifera & Sponges \\
Phylum Cnidaria & \\
Class Anthozoa & \\
Order Actiniaria & Anemones \\
Order Alcyonacea & Soft corals \\
Order Gorgonacea & Sea fans \\
Order Pennatulacea & Sea pens \\
Order Scleractinia & Stony corals \\
Order Antipatharia & Black corals \\
Class Hydrozoa & \\
Order Anthoathecatae & \\
Family Stylasteridae & Hydro corals \\
Habitat indicators & \\
Phylum Echinodermata & \\
Class Crinoidea & Sea lilies \\
Class Asteroidea & Armless stars \\
Order Brisingida & \\
\hline
\end{tabular}

not be possible because many have unknown distributions, many existing species have not been taxonomically classified and new species will certainly be discovered in these relatively unexplored areas. The identification process for many species is also slow and requires great expertise, making it impractical for a rapid evaluation protocol to require identification to species level. We also chose 2 indicator groups of echinoderms that are often found in association with VME taxa and indicate that habitat associated with a VME is present: crinoids (sea lilies) and brisingid sea stars (armless stars). Indicators are valuable because specific habitats of VME taxa are yet to be determined, but the associations between crinoids and brisingid stars and scleractinian corals have been suggested in deep waters off New Zealand from video observations (M. R. Clark pers. obs.). Catchability for some indicator species may be much higher than that of VME taxa, making them a useful proxy. As new taxa associations are identified, new indicator groups can be added to the subset of organisms monitored relative to VME identification. The final group included in the VME evidence protocol is an 'unidentified' coral group. This group is included because, although it may not be possible for some samples to be attributed to a single group, they can still be identifiable as vulnerable coral taxa.

VMEs can also be highly biodiverse areas (Clark et al. 2006, Rogers et al. 2007, Stocks \& Hart 2007).
Although biodiversity can be indexed in many ways (Magurran 2003) and diversity within taxonomic groups is not equal among groups, we considered some measure of biodiversity to be useful. Therefore, we incorporated a weighting factor for catches that showed evidence of multiple taxonomic groups by assigning one point for each vulnerable group encountered. The result is an approach using a simple, fast procedure to determine if a particular catch was likely to be from a VME based on a few key taxonomic groups in the bycatch. The vessel skipper can then utilize the information to comply with permit conditions such as a move-on rule.

Although the chosen groups are large taxonomic categories, some can still be difficult to identify without using complex characteristics. To aid in accurately identifying specimens from these groups, classification guides have been developed specific to the taxa to be monitored, utilizing non-technical and visually apparent characteristics to distinguish the groups (Parker et al. 2008, Tracey et al. 2008). In addition, New Zealand scientific observers are provided with specific training to identify organisms from these groups and they retain specimens for subsequent expert identification and classification guide improvement.

\section{TRIGGERING A MOVE-ON RULE}

Bottom trawls are inefficient at sampling fragile organisms such as corals, which break and shatter when impacted (authors' pers. obs.), and so likely retain a small proportion of the benthos actually impacted (Wassenberg et al. 2002, Mortensen et al. 2008). Furthermore, the sampling efficiency is very likely to be taxa- and size-specific, making conclusions based on trawl bycatch useful for presence-only characterisations. The simple presence of a taxonomic group might therefore be an appropriate trigger for a move-on rule. However, a simple presence/absence criterion could cause a large number of fishing events to trigger the rule and spread benthic impact as discussed. Alternatively, a trigger based on the ability of a particular limiting group to recover from fishery disturbance would be more appropriate, but this requires information on recovery rates, broad-scale distribution, population abundance and selectivity by the fishing gear, which are only available for few areas for some taxa. However, such an approach would help ensure that the evidence encountered provides a fairly high likelihood of encounter with a vulnerable community.

Data available on bycatch in deep-sea trawl fisheries in the South Pacific are also limited, but can provide valuable information from the actual fishery. However, 
bycatch data suffers from unknown catchability, limited historical identification of taxa and limited spatial extent of samples. With these constraints in mind, a threshold weight was determined for each taxonomic group based on the cumulative distribution of bycatch weights observed during an exploratory phase of the New Zealand deep-sea fishery (1998-2002, inside and outside the exclusive economic zone), when VME encounters would be expected to have been most frequent. These bycatch distributions show that most catches were of small amounts, with few large catches. The weights were not standardized for tow duration because no relationship between tow duration and benthic invertebrate bycatch was detectable $\left(\mathrm{R}^{2}=\right.$ 0.014). This is because fishing often targets aggregations of fish near bathymetric features and upper reaches of seamounts, and although tows can be very short, often $<10 \mathrm{~min}$, they can still contact bottom in places where vulnerable species are in high densities. Therefore, the actual observed taxa weight per tow was the most appropriate available measure. It is unknown what bycatch level is biologically significant, but with an emphasis in the SPRFMO on minimizing the overall area of disturbance the median of each historical catch weight distribution was chosen as the threshold weight for each group (Table 2).

We assigned a 3-level relative weighting to each group based on available information about the respective vulnerability of each group to be used when assessing the importance of an observation. Taxa that have known life history characteristics making them vulnerable to fishing activities were scored high. The presence of other groups, perhaps less vulnerable themselves, but which are indicators of habitats often containing vulnerable species, were scored low.

For real-time use at sea, all available information is synthesized using a simple scoring form, which incor-

Table 2. Percentile weights $(\mathrm{kg})$ of catch distribution for each taxonomic group. Data are from observed bottom trawl tows $>200$ m depth from 1998 to 2002, except Gorgonacea and Alcyonacea, which had so few observations that 1998-2007 observations were used. Based on observer reports, unidentified coral was assumed to be Scleractinia. Example: $75 \%$ of observations of Actiniaria were $<100 \mathrm{~kg}$. The 50th percentile value was used for VME score determination

\begin{tabular}{|lcccc|}
\hline \multirow{2}{*}{ Taxonomic group } & \multicolumn{5}{c}{ Percentile weight $(\mathrm{kg})$} & \multirow{2}{*}{ (50th } \\
\cline { 2 - 5 } & 50 th & 75 th & 80 th & 90 th \\
\hline Actiniaria & 5 & 100 & 120 & 171 \\
Antipatharia & 1 & 2 & 2 & 3 \\
Porifera & 50 & 200 & 300 & 750 \\
Unidentified coral & 30 & 100 & 200 & 1000 \\
Hydrocoral & 6 & 80 & 118 & 193 \\
Alcyonacea & 1 & 2 & 2 & 5 \\
Gorgonacea & 1 & 2 & 4 & 20 \\
\hline
\end{tabular}

porates the weights of each vulnerable group, presence of habitat indicators and a gross index of taxonomic diversity into a single score to be used as a trigger (Fig. 1). In developing the scoring process, we considered that the move-on rule should be triggered either by a single very large catch of a vulnerable taxon or if several vulnerable groups were observed, even if the catch is below the group threshold weights.

To evaluate the potential effect of implementing a move-on rule based on these thresholds, we applied the scoring system to benthic bycatch data collected on New Zealand vessels from 2003 to 2007 to estimate the proportion and distribution of bottom trawls that would have triggered the move-on rule. In the SPRFMO area, $87(8.6 \%)$ tows would have triggered the move-on rule during the period (Table 3). In addition, data were collected by scientific observers in the 2008-2009 fishery, when fishers were operating under the new conditions imposed by New Zealand including a move-on rule in certain areas. Of 235 tows, 11 (4.7\%) would have triggered the move-on rule (Table 3 ), had those tows occurred where the move-on rule applied. These tows were spread throughout the fished areas, but there are several areas where clusters of qualifying tows exist (Fig. 2), providing an opportunity for subsequent analyses to use this evidence of repeated encounters with vulnerable taxa to map and designate areas 'likely to support VMEs', as required by the SPRFMO.

\section{EVIDENCE VERSUS DESIGNATION OF A VME}

The move-on rule adopted by New Zealand is triggered by operational 'evidence' of interaction with VME taxa, but does not in itself designate the actual presence of a VME. Without knowledge of the distribution, density or taxonomic composition of the community, the precautionary designation of a VME is a management decision. Under the SPRFMO interim measures, designation of an area as 'known or likely to support VMEs' carries with it an obligation to implement suitable and effective fishery management mea-

Table 3. Comparison of the number of 2003-2007 tows qualifying as evidence of a vulnerable marine ecosystem (VME) using the New Zealand VME Evidence Process form based on 1998 to 2002 50th percentile weight threshold estimates (see Fig. 1)

\begin{tabular}{|lcc|}
\hline & 2003-2007 & 2008 \\
\hline Total number of tows & 1010 & 235 \\
Tows with VME score $\geq 3$ & 87 & 11 \\
\% tows with VME score $\geq 3$ & 8.6 & 4.7 \\
Number with VME taxa & 211 & 77 \\
\hline
\end{tabular}




\section{Vulnerable Marine Ecosystem Evidence Process (Version 1.0 - Apr 08)}

1. Trip, tow, and vessel information

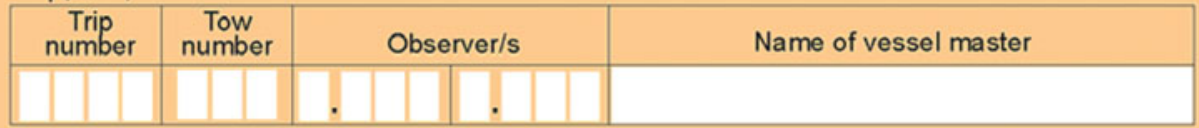

2. Date, time, and position that hauling of the gear commenced

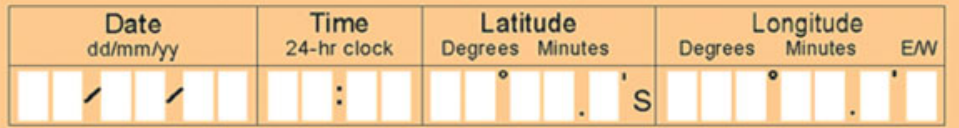

3. Instructions

Assess the total weights of all organisms whether dead or alive in each of the relevant taxonomic groups and record in Section 4. If the Observed Weight of a taxonomic group is greater than (not equal to) the Threshold Weight, write the VME Indicator Score for that group in the "Score" Column.

If a taxonomic group is present, but the Observed Weight is not greater than the Threshold Weight, tick in the "Tick" column. Sum the scores and count the ticks. Record these totals at the bottom of the columns. Add the Sum of scores to the Count of ticks and record it as the Total VME Indicator Score.

If the Total VME Indicator Score is 3 or greater, the area is considered to have Evidence of a Vulnerable Marine Ecosystem.

The taxonomic groups recorded on this form may not be a complete record of all benthic material present in the tow.

4. Relevant taxonomic groups, weights, and scores

\begin{tabular}{|c|c|c|c|c|c|c|c|}
\hline Taxonomic Group & Code & $\begin{array}{l}\text { Method of } \\
\text { Weighting }\end{array}$ & $\begin{array}{l}\text { Observed } \\
\text { Weight } \\
\text { (kg) }\end{array}$ & $\begin{array}{c}\text { Threshold } \\
\text { Weight } \\
\text { (kg) }\end{array}$ & $\begin{array}{l}\text { VME } \\
\text { Indicator } \\
\text { Score }\end{array}$ & $\begin{array}{c}\text { Threshold } \\
\text { Weight } \\
\text { exceeded }\end{array}$ & $\begin{array}{c}\text { Tick if not } \\
\text { scored but } \\
\text { present }\end{array}$ \\
\hline PORIFERA & ONG & & . & 50 & 3 & & \\
\hline \multicolumn{8}{|l|}{ CNIDARIA } \\
\hline \multicolumn{8}{|l|}{ Anthozoa (class) } \\
\hline Actiniaria (order) & ATR & & . & 0 & 1 & & \\
\hline Scleractinia (order) & SIA & & . & 30 & 3 & $\stackrel{\infty}{5}$ & 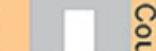 \\
\hline Antipatharia (order) & $\mathrm{COB}$ & & . & 1 & 3 & F & $\stackrel{\text { ᄅ }}{=}$ \\
\hline Alcyonacea (order) & SOC & & . & 1 & 3 & & 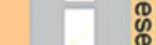 \\
\hline Gorgonacea (order) & GOC & & . & 1 & 3 & & 홋 \\
\hline Pennatulacea (order) & PTU & & . & 0 & 1 & & \\
\hline Hydrozoa (class) & HDR & & . & 6 & 3 & & \\
\hline Unidentified Coral & $\mathrm{COU}$ & & . & 0 & 1 & & \\
\hline \multicolumn{8}{|l|}{ ECHINODERMATA } \\
\hline Crinoidea (class) & CRI & & & 0 & 1 & & \\
\hline Brisingida (order) & BRG & & & 0 & 1 & & I \\
\hline
\end{tabular}

5. Vessel notification

As soon as the form is completed for any tow provide a copy to the person in charge of the vessel.

\begin{tabular}{|c|c|c|c|}
\hline Name (if not vessel master) & Received by person in charge (signature) & $\begin{array}{c}\text { Date received } \\
\text { (dd/mm/y) }\end{array}$ & $\begin{array}{c}\text { Time received } \\
(24-\mathrm{hr} \mathrm{clock})\end{array}$ \\
\hline & & $/ /$ & $:$ \\
\hline
\end{tabular}

Fig. 1. Vulnerable Marine Ecosystem Evidence Process form as developed by the Ministry of Fisheries for use by New Zealand bottom trawl vessels fishing within the South Pacific Regional Fishery Management Organisation (SPRFMO) convention area (Ministry of Fisheries 2008) 


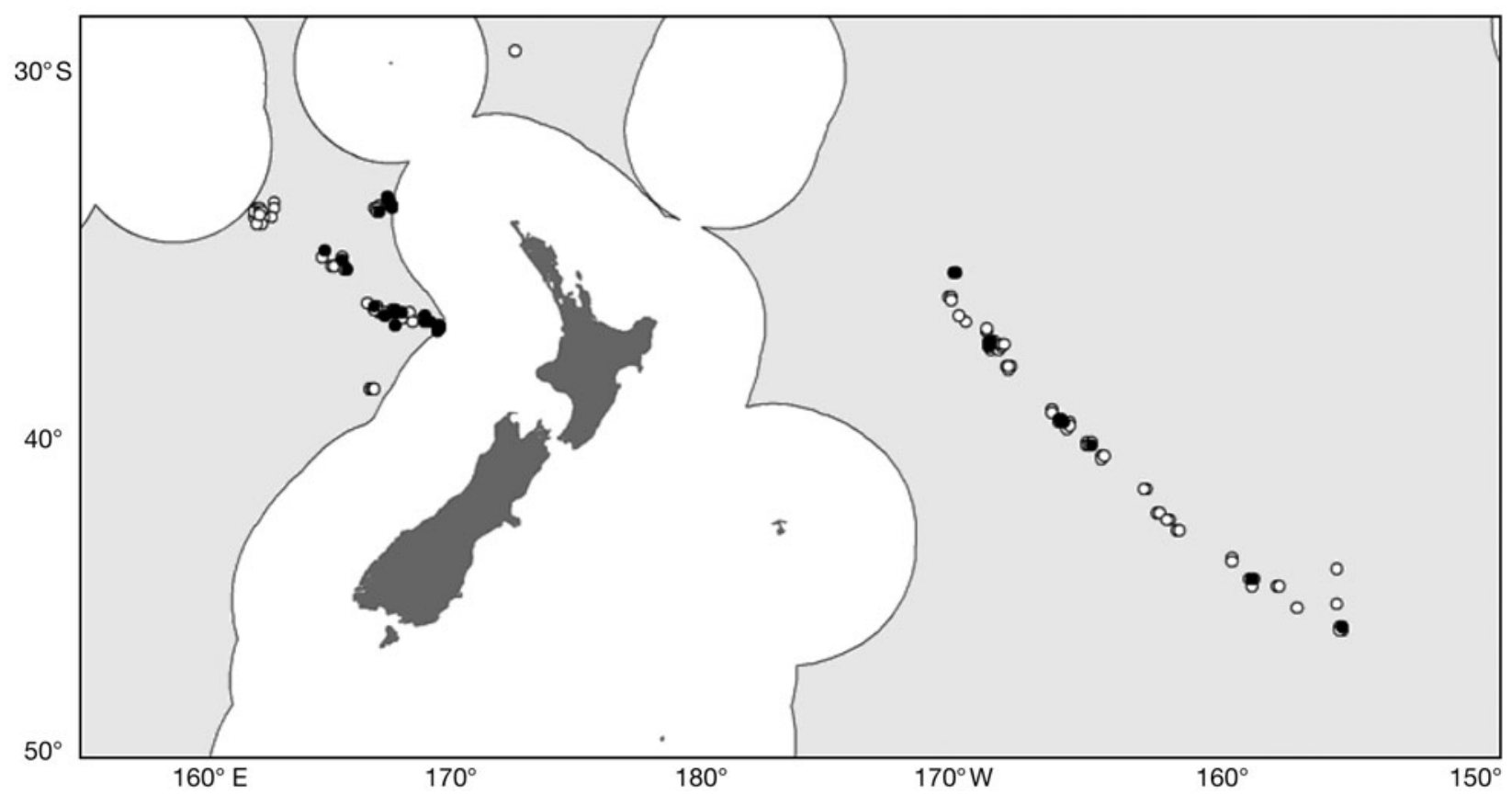

Fig. 2. Observed bottom trawl tows (2003-2007) within the South Pacific Regional Fishery Management Organisation area (light grey shading) with a vulnerable marine ecosystem (VME) indicator score of $\geq 3$ based on the 50th percentile thresholds from 1998 to 2002 (black circles), or tows with score <3 (white circles) ( $\mathrm{N}=1010$ tows)

sures to prevent significant impact on such an area. This would need to be done by the fisheries regulating authority and could consist of many possible management actions. For example, managers could impose special research and data collection requirements (e.g. a camera deployment or collection of oceanographic data from the site), restrict gear types or close the area to bottom contact gears; each with their own implementation, monitoring and enforcement requirements. It is important to distinguish between these 2 levels of protection, as a move-on rule offers a quick, short-term conservation action at sea to limit the immediate impact on areas which appear to support VME taxa, and VME designation is a deliberative, long-term assessment of vulnerability over larger spatial scales incorporating all the scientific information available, followed by an appropriate management response.

\section{CRITERIA TO DESIGNATE A VME}

Despite progress made in defining generic characteristics of VMEs by the FAO (2008), practical working definitions of VMEs are still rather vague and widely debated. There is general agreement that areas with certain characteristics, such as containing high densities of structure-forming species that are vulnerable to fishing gears and taking many decades to recover would qualify as a VME. As an area decreases in size, diversity, species density and structural complexity, consensus becomes more difficult to achieve. There is also little guidance on information requirements to identify such areas. Direct observations are rare and often from localised research surveys. All that is available for most oceanic areas are ancillary biogeographic data that have been correlated with the presence of vulnerable species in other studies, such as the occurrence of a seamount with a physical habitat shown elsewhere to be suitable for stony corals (Rogers et al. 2007, Tittensor et al. 2009). Identifying and protecting these areas in a structured way requires clear definitions, criteria and objectives (Rogers et al. 2008).

With very slow recovery of impacted areas (e.g. Kaiser et al. 2006, Lumsden et al. 2007), additional fishing inevitably creates additional impact either by expanding the disturbed areas or by preventing recovery in repetitively fished areas (Constable and Holt 2007). The evidence for extremely low recovery rates for these organisms means that a typical 'sustainable yield' type of management scheme would not be a responsible approach. What is more important is to ensure that such impacts remain 'not significant' across the spatial scale of the habitats concerned. This will primarily require limiting the scale of impact of the fisheries, perhaps most effectively by protecting adequate and representative seabed areas 
from fishing disturbance by means of spatial closures (FAO 2008). Repeated trawling in exactly the same areas will have diminishing additional impacts within those areas. Accurately tracking the footprint of disturbed habitat through time can provide an estimate of the spatial extent of the impact on benthic habitat, but not an estimate of the proportion of habitat affected, nor of recovery rate of organisms in the impacted area. Assessing whether areas protected were adequate and representative requires information about population distribution, connectivity and recovery rates, attributes that are unknown for the majority of vulnerable taxa. To address this problem, at some point managers must set a priori a total permissible impact level and constrain fishing impacts to that level, effectively creating impacted fishing areas and undisturbed areas.

During the evaluation of benthic impact assessments by regulating authorities, any available information from previous years of fishing in an area (such as the 20-minute spatial blocks used to define the SPRFMO bottom fishing footprint areas), research or survey information, information from adjacent areas and information from habitat modelling exercises should be utilized to re-assess the significance of any proposed impact from fishing. To ensure effectiveness of any limitation of fishing area or designation of closed areas, it is essential that such benthic habitat protection measures in the high seas are a truly international effort and that management incorporates measures to prevent illegal, unreported and unregulated fishing.

The long-term designation of an area as a VME will therefore have to be made internationally using all the information available for an area. The following criteria provide a process to prioritize areas relative to protection status. The more criteria that are met, the more an area needs long-term protection from interactions with fishing gears and should be designated as a VME:

1. Existing data from historical fishing records or scientific research samples show records of vulnerable taxa.

2. Estimates from habitat suitability models indicate the region is likely to contain groups listed in Table 1. This coarse criterion targets larger regions that may describe a pattern in the distribution of these vulnerable organisms. It also provides a coarse resolution tool to extrapolate observations in one area to nearby areas with similar characteristics.

3. The area shows repetitive encounters with any of the taxonomic groups in Table 1, establishing that structure-forming organisms occur at that broad location.

4. The catch of a vulnerable taxon is much higher than the fishery norm when that group is encountered, suggesting that the area may contain high densities of vulnerable taxa. New Zealand defines the 'norm' as the 50th percentile weight (the median) from the observed catch distribution of a given taxon.

5. The area is relatively isolated compared to other areas with similar physical and biological characteristics, and therefore potentially supports species endemic to that area. Evidence linking isolation with endemism is inconsistent at present (McClain 2007), even with the obvious bias of higher endemism resulting from undersampling over broad areas (Stocks \& Hart 2007). Much of this confusion may yet be explained by incorporating dispersal mechanisms for various taxa and oceanographic regions. This criterion targets the theoretical relationship between endemism and isolation, giving extra weight to areas that may contain unique species. It could be implemented by calculating the distance between a disturbed site and the nearest site with similar habitat characteristics (i.e. depth range, temperature, productivity, etc.). This could be determined as part of maximum entropy modelling efforts (e.g. Tittensor et al. 2009).

6. The area has a high degree of diversity and species richness relative to other managed areas. For an area of similar size (e.g. fishing site, defined spatial extent or 20-minute management block), an index of taxonomic distinctness (Clarke \& Warwick 2001) can be generated as a metric so that more taxonomically diverse areas are recognized. The taxonomic diversity index is a simple weighting scheme that counts the number of taxonomic steps between pairs of species (groups) for the specimens of VME indicator taxa observed in a predefined area. It is sensitive to taxonomic resolution, but if this is consistent across all areas it is a useful index for evaluating which areas show relatively more diverse assemblages of VME taxa.

\section{LONG-TERM PLAN FOR EFFECTIVE PROTECTION}

In the absence of data from research surveys, identification of areas to be designated as VMEs will likely need to rely on fishery bycatch data. In the short term, protection will be a balance between the potential impacts to VMEs from exploratory fishing and collecting information to inform the development of proposals for representative spatial closures. The low productivity rates for many deep-sea species suggest that areas would need to be permanently protected, which would preclude the development of new fisheries or other human impacts in the future.

In the long term, RFMOs should encourage and support the development of databases with information on biodiversity, species-level catch, effort, location and seafloor characteristics (such as bathymetry or habitat 
type). Such databases should also contain environmental and physical information from a number of scientific and government sources (sensu Rowden et al. 2005 , 2008). Databases used to support the prediction of vulnerable areas should combine physical characteristics (location, depth and substrate type) with biological (productivity, biodiversity indices, species composition and relative abundance) as well as derived characteristics (representativeness, degree of spatial isolation and productivity of species present). Because of specific habitat requirements for filter-feeding invertebrates, and their association with topographical features like seamounts, these vulnerable species have been found to be patchily distributed (Koslow et al. 2001, Rogers et al. 2008). Nonetheless, data from the few scientifically sampled locations in the South Pacific can be integrated with broader-scale environmental data to predict the distribution of areas suitable as habitats for similar vulnerable species based on techniques such as environmental niche factor analysis or maximum entropy modelling (Clark et al. 2006, Tittensor et al. 2009). These areas could be then targeted for scientific investigation using direct sampling (Constable \& Holt 2007, CCAMLR 2007), either from fishing vessels or during future research voyages. Ultimately, the goal should be to provide the basis for the establishment of specific spatial closures designed to protect adequate and representative proportions of VMEs.

Acknowledgements. This work was funded by the New Zealand Ministry of Fisheries (IFA200702). D. Fisher provided the observer data and D. Tracey assisted with invertebrate bycatch data and interpretation. We thank the anonymous reviewers for thoughtful suggestions that greatly improved the manuscript.

\section{LITERATURE CITED}

Adkins JF, Henderson GM, Wang SL, O'Shea S, Mokadem F (2004) Growth rates of the deep-sea scleractinia Desmophyllum cristagalli and Enallopsammia rostrata. Earth Planet Sci Lett 227:481-490

Auster PJ (2005) Are deep-water corals important habitats for fishes? In: Freiwald A, Roberts JM (eds) Cold-water corals and ecosystems. Springer-Verlag, Berlin, p 747-760

Buhl-Mortensen L, Mortensen PB (2005) Distribution and diversity of species associated with deep-sea gorgonian corals off Atlantic Canada. In: Freiwald A, Roberts JM (eds) Cold-water corals and ecosystems. Springer-Verlag, Berlin, p 849-879

CCAMLR (Commission for the Conservation of Antarctic Marine Living Resources) (2007) Conservation Measure 22-06. Schedule of Conservation Measures in Force 2007/ 08. CCAMLR, Hobart

Clark MR, Koslow JA (2007) Impacts of fishing on seamounts. In: Pitcher TJ, Hart PJB, Morato T, Santos R, Clark M (eds) Seamounts: ecology, fisheries and conservation. Blackwell Fisheries and Aquatic Resources Series 12, Blackwell Scientific, Oxford, p 413-441
Clark MR, Tittensor D, Rogers AD, Brewin P and others (2006) Seamounts, deep-sea corals and fisheries: vulnerability of deep-sea corals to fishing on seamounts beyond areas of national jurisdiction. UNEP-WCMC, Cambridge

Clarke KR, Warwick RM (2001) A further biodiversity index applicable to species lists: variation in taxonomic distinctness. Mar Ecol Prog Ser 216:265-278

Constable A, Holt R (2007) Bottom fishing in high seas areas of CCAMLR. Document SC-CAMLR-XXVI/10. CCAMLR, Hobart

FAO (Fisheries and Agriculture Organization) (2008) International guidelines for the management of deep sea fisheries in the high seas. FAO Technical Consultation Document, FAO, Rome

Kaiser MJ (1998) Significance of bottom-fishing disturbance. Conserv Biol 12:1230-1235

Kaiser MJ, Clarke KR, Hinz H, Austen MCV, Somerfield PJ, Karakassis I (2006) Global analysis of response and recovery of benthic biota to fishing. Mar Ecol Prog Ser 311:1-14

Koslow JA, Gowlett-Holmes K, Lowry JK, O'Hara T, Poore GCB, Williams A (2001) Seamount benthic macrofauna off southern Tasmania: community structure and impacts of trawling. Mar Ecol Prog Ser 213:111-125

Lumsden SE, Hourigan TF, Bruckner AW, Dorr G (eds) (2007) The State of Deep Coral Ecosystems of the United States. NOAA Tech Memo CRCP-3, Silver Spring, MD

Magurran AE (2003) Measuring biological diversity. Blackwell Science, Oxford

McClain CR (2007) Seamounts: Identity crisis or split personality? J Biogeogr 34:2001-2008

Ministry of Fisheries (2008) Vulnerable Marine Ecosystem Evidence Process version 1.0, Ministry of Fisheries Observer Services. New Zealand Ministry of Fisheries, Wellington

Mortensen PB, Buhl-Mortensen L, Gebruk AV, Krylova EM (2008) Occurrence of deep-water corals on the MidAtlantic Ridge based on MAR-ECO data. Deep-Sea Res Part II 55:142-152

Parker S, Tracey D, Mackay E, Mills S and others (2008) Classification guide for potentially vulnerable invertebrate taxa in the Ross Sea long-line fishery. Document WGFSA-08/19. CCAMLR, Hobart

Penney A, Parker SJ, Brown J, Cryer M, Clark M, Sims B (2008) New Zealand Implementation of the SPRFMO Interim Measures for High Seas Bottom Trawl Fisheries in the SPRFMO Area. Document SPRFMO-V-SWG-09. South Pacific Regional Fishery Management Organisation, Wellington

Penney AD, Parker SJ, Brown J (2009) Protection measures implemented by New Zealand for vulnerable marine ecosystems in the South Pacific Ocean. Mar Ecol Prog Ser 397:341-354

> Roark EB, Guilderson TP, Dunbar RB, Fallon SJ, Mucciarone DA (2009) Extreme longevity in proteinaceous deep-sea corals. Proc Natl Acad Sci USA 106:5204-5208

Rogers AD, Baco A, Griffiths H, Hart T, Hall-Spencer JM (2007) Corals on seamounts. In: Pitcher TJ, Morato T, Hart PJB, Clark MR, Haggan N, Santos RS (eds) Seamounts: ecology, fisheries, and conservation. Blackwell Fisheries and Aquatic Resources Series 12. Blackwell Scientific, Oxford, p 141-169

Rogers AD, Clark MR, Hall-Spencer JM, Gjerde KM (2008) The science behind the guidelines: a scientific guide to the FAO draft international guidelines (December 2007) for the management of deep-sea fisheries in high seas and examples of how the guidelines may be practically implemented. IUCN, Switzerland 
Rowden AA, Clark MR, Wright IC (2005) Physical characterisation and a biologically focused classification of 'seamounts' in the New Zealand region. NZ J Mar Freshw Res 39:1039-1059

Rowden AA, Oliver M, Clark MR, MacKay K (2008) New Zealand's 'SEAMOUNT' database: recent updates and its potential use for ecological risk assessment. Aquatic Environment and Biodiversity Report No. 27, Ministry of Fisheries, Wellington

SPRFMO (South Pacific Regional Fishery Management Organisation) (2007) SPRFMO III Report-Annex F. Interim measures adopted by participants in negotiations to establish South Pacific Regional Fisheries Management Organisation. Reñaca, Chile, 30 Apr-4 May 2007. SPRFMO, Wellington

SPRFMO (2008) Bottom fishing activities by New Zealand vessels fishing in the high seas in the SPRFMO area during 2008 and 2009. Document SP-7-SWG-DW-01. SPRFMO, Wellington

Stocks K, Hart PJB (2007) Biogeography and biodiversity of seamounts. In: Pitcher TJ, Morato T, Hart PJB, Clark MR, Haggan N, Santos RS (eds) Seamounts: ecology, fisheries, and conservation. Blackwell Fisheries and Aquatic Resources Series 12. Blackwell Scientific, Oxford, p 255-281

Submitted: February 23, 2009; Accepted: May 16, 2009
Tittensor DP, Baco-Taylor AR, Brewin P, Clark MR and others (2009) Predicting global habitat suitability for stony corals on seamounts. J Biogeogr 36:1111-1128

Tracey DM, Neil H, Marriott P, Andrews AH, Cailliet GM, Sanchez JA (2007) Age, growth, and age validation of two genera of deep-sea bamboo corals (Family Isididae) in New Zealand waters. Bull Mar Sci 81:393-408

Tracey DM, Parker SJ, Mackay E, Anderson O, Ramm K (2008) Classification guide for potentially vulnerable invertebrate taxa in the SPRFMO Area. New Zealand Ministry of Fisheries, Wellington

UNGA (United Nations General Assembly) (2007) Resolution 61/105. Sustainable fisheries, including through the 1995 Agreement for the Implementation of the Provisions of the United Nations Convention on the Law of the Sea of 10 December 1982 relating to the Conservation and Management of Straddling Fish Stocks and Highly Migratory Fish Stocks, and related instruments. UNGA A/RES/61/105. Available at: www. un.org/Depts/los/general_assembly/general_assembly_ resolutions.htm

Wassenberg TJ, Dews G, Cook SD (2002) The impact of fish trawls on megabenthos (sponges) on the north-west shelf of Australia. Fish Res 58:141-151

Proofs received from author(s): September 29, 2009 